\title{
Prevalence of bovine tuberculosis in beef feedlot of Borena cattle by using comparative intradermal skin test, Adama, Ethiopia
}

\author{
Tefera Woldemariam ${ }^{1,2^{*}}$, Gezahegne Mamo ${ }^{1}$, Temesgen Mohammed ${ }^{3}$ and Gobena \\ Ameni $^{3}$ \\ ${ }^{1}$ Hawassa University, School of Veterinary Medicine, P.O. Box 05, Hawassa, Ethiopia \\ ${ }^{2}$ Department of Microbiology, Immunology and Veterinary Public Health, College of Veterinary \\ Medicine and Agriculture, Addis Ababa University, Bishoftu, Ethiopia
}

${ }^{3}$ Aklilu Lemma Institute of Pathobiology, Addis Ababa University, Addis Ababa Ethiopia

*Corresponding author: Hawassa University, School of Veterinary Medicine, P.O. Box 05, Hawassa, Ethiopia.Email: teferailigo@gmail.com

http://dx.doi.org/10.4314/evj.v20i2.2

\begin{abstract}
A cross-sectional study was carried out from August to November, 2015 among feedlot cattle in and around Adama export feedlot farms by using comparative intradermal tuberculin skin test to estimate the prevalence of bovine tuberculosis and to assess the associated risk factors. The individual animal prevalence with 4 mm cut-off point and with $2 \mathrm{~mm}$ cut-off point was $4.39 \%$ (95\% CI: $2.59-6.19)$ and 9.58\% (95\% CI: 6.99-12.16), respectively. In univariate logistic regression analysis, older animals (OR=7.11, 95\% CI: 1.7-29.8), cattle from Yabello market $(\mathrm{OR}=5.66$, 95\% CI: 2.4-13.2) and cattle in feedlot $5(\mathrm{OR}=2.65,95 \% \mathrm{CI}: 1.03-6.8)$ were more likely to be tuberculin reactors than younger animals, cattle originated from Dubliqu market and those from feedlot I, respectively. In multivariable logistic regression, however, only feedlot farm difference showed a statistical significance difference among the groups with the $\mathrm{OR}=3.4$ (95\% CI: 1.2-9.5), while other factors were not statistically significant. In conclusion, the study revealed the occurrence of bovine tuberculosis in Adama export feedlot farms composed mainly of Borena cattle breeds which were established for export of fattened live beef cattle and hence, the findings of this study warrants the need to design a farm based control strategies at feedlot level and testing of animals during the purchase of the cattle at the market place of the animals.
\end{abstract}

Keywords: Bovine tuberculosis, Comparative tuberculin testing, Feedlot farm, Prevalence, Risk factor 


\section{Introduction}

Bovine tuberculosis (BTB) is a chronic infectious disease of cattle characterized by the formation of granulomatous nodules which is caused by Mycobacterium bovis. BTB has been controlled in developed countries through test-andslaughter method; however, the disease poses a significant problem to the economy of the livestock sub-sector and remains a potential public health threat in developing countries where controlling programs are lacking (Cosivi et al., 1998). Infection of livestock with BTB has an estimated global cost of €2 billion annually (Garnier et al., 2003); due mostly to the lack of BTB control in developing countries, where infection is endemic, resulting in reduced productivity of livestock (Richardson et al., 2014).

Ethiopia has the largest livestock population in Africa, With 52.1 million cattle, 24.2 million sheep, 22.6 million goats, 987, 000 camels, 44.9 million poultry and nearly 5 million beehives (MOA, 2013), that contributes to the livelihoods of $60-70 \%$ of the population (Halderman, 2004). In Ethiopia, BTB is endemic in cattle with the prevalence varies from 0.8 to $46.8 \%$ depending on the geographical location, breed and the husbandry practices based on abattoir and tuberculin skin tests (Gobena Ameni et al., 2003; Berg et al., 2009; Demelash Bifa et al., 2010; Alemayehu Regassa et al., 2010; Tschopp et al., 2010), with extensive rural and pastoral setting showing low prevalence as compared to intensive dairy farms (Gobena Ameni et al., 2007, Gezahegne Mamo et al., 2013).

The existing information on BTB so far in Ethiopia was mainly in dairy animals and in extensive traditional and pastoralist production system. However, with increasing beef demand both in-country and abroad, there is a growing number of feedlot in central Ethiopia where cattle brought together from different sources and geographic location to the feedlots located mainly in Adama and its surrounding towns of East Shewa central Ethiopia. So far, in East Shewa Central, Ethiopia, there is no study carried out to determine the prevalence of bovine tuberculosis and its associated risk factors in beef animals kept under feedlots conditions. The present study, therefore, was designed to investigate the prevalence of bovine tuberculosis in beef cattle kept in feedlots in and around Adama town of central Ethiopia and to assess the potential determinant risk factor using comparative intradermal skin test method. 


\section{Materials and Methods}

\section{Study area}

This study was conducted at Adama town in East Shewa zone of central Ethiopia in five feedlot farms to determine the prevalence of bovine tuberculosis and associated risk factors from August to December 2015. Adama town is located at $8.54^{\circ} \mathrm{N} 39.27^{\circ} \mathrm{E}$ at an elevation of 1712 meters above sea level, $99 \mathrm{~km}$ southeast of Addis Ababa. The city is situated along the road that connects Addis Ababa with Djibouti. The total population of Adama is estimated 450,000. In Adama and its surrounding area there are about 97 feedlot farms (Adama 44, Awash Melkasa 6, Dera 26, and Wonji 21). In this study the beef cattle feedlots were selected according to the distance from one selected site to another, number of beef cattle that the farm owns and the presence of beef cattle during study period (two farms from Adama, one farm from Awash Melkasa, One farm from Dera, and One farm from Wonji site), so based on these criteria a total of five feedlot farms were selected. Each selected farm has got 500-1200 beef cattle kept for live animal export purpose mainly to Middle East countries. In 20142015 from the study site feedlot farms about 561,000 cattle were exported to the Middle East countries (ESMoA, 2015). The source of cattle for these feedlot farms were mainly from the Borena zone, South Ethiopia and the breed were mainly Borena breeds of cattle.
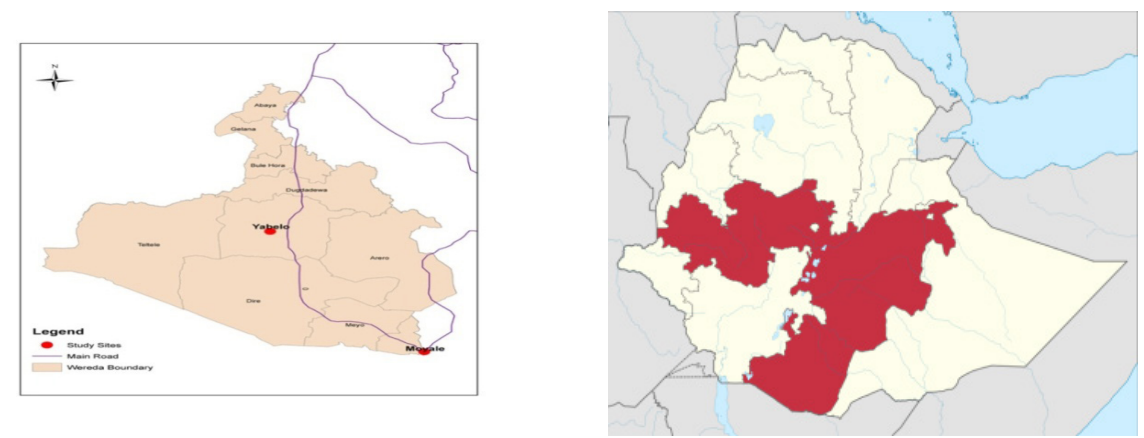

Figure 1: Map of the origin of animal for the feedlots (Borona zone, Oromia Region shaded red) 


\section{Study design}

A cross sectional study was conducted in five feedlot farms found in Adama and its surround area from August 2015 to December 2015. The five feedlot farms were selected based on the presence of cattle in the farms during the study period, the willing of owners, the distance of sites and the population of animals. A total of 501 Borena cattle were included and in each feedlots, individual cattle were selected randomly based on individual animals identification number record and cattle population mentioned above in each farms. The feedlot farms mainly consist of only male cattle with age ranging from 1.5-6 years old.

\section{Sample size and study animals}

A total of 501 cattle which have no clinical symptom of any disease were included. Study animal related information on each tested cattle such as animal origin, age and body condition score were collected and recorded at the time of the test. Sample size was determined based on Thrustfield (1995). Since there was no previous study on feedlot cattle in Ethiopia, an expected $50 \%$ prevalence of BTB in feedlot cattle with $95 \%$ confidence interval and $5 \%$ required precision. According to this, the calculated sample size was 384 and the sample size was increased to 501 cattle considering the dropout and missing on the second reading. For each farm number of animal tested were proportionally distributed.

\section{Comparative intradermal tuberculin skin test (CIDT)}

CIDT was carried out by injecting both bovine purified protein derivative (PPD) and avian PPD (Prionics Lelystad B.V., Platinastraat 33, 8211 AR Lelystad, The Netherlands). Two sites on the skin of the mid-neck of the cattle, $12 \mathrm{~cm}$ apart, were shaved, and skin thickness was measured with a caliper. One site was injected with an aliquot of $0.1 \mathrm{ml}$ of $3000 \mathrm{IU} / \mathrm{ml}$ bovine PPD into the dermis, and the other was similarly injected with $0.1 \mathrm{ml}$ of $2,500 \mathrm{IU} / \mathrm{ml}$ avian PPD. After $72 \mathrm{~h}$, the skin thickness at the injection sites was measured and recorded. Results were interpreted according to the recommendations of the Office International des Epizooties (OIE, 2009) at $\geq 4 \mathrm{~mm}$ cut-off and also at $\geq 2 \mathrm{~mm}$ cut-off (Gobena Ameni et al., 2008). Thus, at cut-off $\geq 4 \mathrm{~mm}$, if the increase in skin thickness at the injection site for bovine PPD (PPD-B) was greater than the increase in skin thickness at the injection site for avian PPD 
(PPD-A) and PPD-B minus PPD-A was less than $2 \mathrm{~mm}$, between 2 and $4 \mathrm{~mm}$, or $4 \mathrm{~mm}$ and above, the animal was classified as negative, doubtful, or positive for BTB, respectively. At cut-off $\geq 2 \mathrm{~mm}$, if the difference between B and A was greater or equal to $2 \mathrm{~mm}$, the animal was considered as positive, while if the difference is less than $2 \mathrm{~mm}$, the animal was considered as negative. When the change in skin thickness was greater at PPD A injection site, the animal was considered positive for mycobacterium species other than Mycobacterium tuberculosis complex. A herd was considered as positive if it had at least one tuberculin reactor animal.

\section{Body condition scoring and age determination}

Body condition scoring was made using a method developed for Zebu cattle (Nicholson and Butterworth, 1986). Accordingly, on the basis of observation of anatomical parts such as vertebral column, ribs, and spines, the study animals were classified as lean (1), medium (2 and 3) or good (4 and greater). Age of the study animals was determined by using the dental eruption and wear as described by De Lanta and Habel (1986) and for this study animals were categorized as young age $\leq 2$ and adult age $>2$.

\section{Data management and analysis}

Data were classified, filtered, coded using Microsoft Excel sheet and was transferred and analyzed using STATA version 11 (Stata Corp., Collage station, TX). Pearson chi- square was used to evaluate the statistical significance of the associations of different categorical variables with tuberculin skin test results. Bivariate and multivariable logistic regression analyses were performed to quantify crude and adjusted effects of pre-specified risk factors on tuberculin reactivity. P-value less than $5 \%$ was considered statistically significant. In cases of estimating the effect of different risk factors in terms of odds ratio (OR) with corresponding 95\% confidence interval, statistical significance was assumed if the confidence interval did not include one among its values.

\section{Results}

\section{Individual animal prevalence}

On the basis of CIDT, the prevalence of BTB with $4 \mathrm{~mm}$ cut-off point and with 2 mm cut-off point was $4.39 \%$ (95\% CI: $2.59-6.19)$ and $9.58 \%,(95 \%$ CI:6.9912.16) respectively. At $4 \mathrm{~mm}$ cut-off point, there were statistically significant 
differences in proportions of bovine positive reactor animals between the two age categories $\left(\mathrm{X}^{2}=6.79, \mathrm{p}=0.045\right)$ in which a higher bovine positive reactors were observed in adult cattle than young one. While there was no statistical difference in the proportion of bovine tuberculin positivity between groups in relation to feedlot farm, origin of the animal and body condition score $(\mathrm{P}>0.05)$ (Table 1).

Table 1: Association of different risk factors to skin test positivity at $4 \mathrm{~mm}$ cutoff point for bovine tuberculosis in East Shewa, Central Ethiopia

\begin{tabular}{|c|c|c|c|c|}
\hline Variables & $\begin{array}{l}\text { No of cattle } \\
\text { examined }\end{array}$ & No of positive (\%) & $\mathrm{X}^{2}$ & P-value \\
\hline \multicolumn{5}{|l|}{ Farm } \\
\hline I & 90 & $6(6.67)$ & 6.79 & 0.147 \\
\hline II & 111 & $7(6.31)$ & & \\
\hline III & 100 & $0(0.00)$ & & \\
\hline IV & 100 & $5(5.00)$ & & \\
\hline $\mathrm{V}$ & 100 & $4(4.00)$ & & \\
\hline \multicolumn{5}{|l|}{ Origin } \\
\hline Dubluq & 289 & $9(3.11)$ & 3.95 & 0.139 \\
\hline Moyale & 155 & $8(5.16)$ & & \\
\hline Yabello & 57 & $5(8.77)$ & & \\
\hline \multicolumn{5}{|l|}{ Age } \\
\hline$\leq 2$ & 109 & $1(0.92)$ & 4.00 & $0.045^{*}$ \\
\hline$>2$ & 392 & $21(5.36)$ & & \\
\hline \multicolumn{5}{|l|}{ BCS } \\
\hline Medium & 16 & $0(0.00)$ & 0.76 & 0.384 \\
\hline Good & 485 & $22(4.39)$ & & \\
\hline Total & 501 & $22(4.39)$ & & \\
\hline
\end{tabular}

$\overline{\mathrm{BCS}}=$ Body condition scoring. 
At $2 \mathrm{~mm}$ cut-off point, statistically high significant differences were observed in proportion of bovine positive reactors between the five feedlot farms $\left(x_{2}=27.18\right.$, $\mathrm{p}=<0.001)$; source of origin $\left(\chi^{2}=22.22, \mathrm{p}=<0.001\right)$; age categories $(\chi 2=9.65$, $\mathrm{p}=0.002)$. But in relation to body condition score, there was no statistically significant difference between the groups $(\chi 2=0.2, \mathrm{P}=0.687)$ (Table 2$)$.

Table 2: Association of different risk factors to skin test positivity at $2 \mathrm{~mm}$ cutoff point for bovine tuberculosis in East Shewa, Central Ethiopia

\begin{tabular}{|c|c|c|c|c|}
\hline Variable & $\begin{array}{l}\text { No of cattle } \\
\text { examined }\end{array}$ & $\begin{array}{c}\text { No of positive } \\
(\%)\end{array}$ & $X^{2}$ & p-value \\
\hline \multicolumn{5}{|l|}{ Farm } \\
\hline I & 90 & 15(16.67) & 27.18 & $<0.001^{*}$ \\
\hline II & 111 & $20(18.02)$ & & \\
\hline III & 100 & $0(0.00)$ & & \\
\hline IV & 100 & $6(6.00)$ & & \\
\hline V & 100 & $7(7.00)$ & & \\
\hline \multicolumn{5}{|l|}{ Origin } \\
\hline Dubluq & 289 & $13(4.50)$ & 22.22 & $0.001^{*}$ \\
\hline Moyale & 155 & $23(14.84)$ & & \\
\hline Yabelo & 57 & $12(21.05)$ & & \\
\hline \multicolumn{5}{|l|}{ Age } \\
\hline$\leq 2$ & 109 & $2(1.83)$ & 9.65 & $0.002^{*}$ \\
\hline$>2$ & 392 & $46(11.73)$ & & \\
\hline \multicolumn{5}{|l|}{ BCS } \\
\hline Medium & 16 & $2(12.50)$ & 0.2 & 0.687 \\
\hline Good & 485 & $46(9.48)$ & & \\
\hline
\end{tabular}


In logistic regression analysis of tuberculin reactors with various host and environment related factors at $4 \mathrm{~mm}$ cut-off point are insignificant. In univariate logistic regression analysis, older animals (OR=7.11, 95\% CI: 1.729.8), cattle from Yabello market (OR=5.66, 95\% CI: 2.4-13.2) and cattle in feedlot $5(\mathrm{OR}=2.65,95 \% \mathrm{CI}: 1.03-6.8)$ were more likely to be tuberculin reactors than younger animals, cattle originated from Dubliqu market and those from feedlot I, respectively. In multivariable logistic regression, however, only feedlot farm difference showed a statistical significance difference among the groups with the OR=3.4 (95\% CI: 1.2-9.5), while other factors were not statistically significant (Table 3). Although it was not significant, older animals showed 2.1 times the odds of being tuberculin reactor than younger animals $(\mathrm{OR}=2.10$; 95\% CI: 0.46-9.59). At $\geq 4 \mathrm{~mm}$ cut-off points, there was no statistical significance difference in the proportion of bovine tuberculin positivity between groups in relation to the different variables considered.

Table 3: Multivariable logistic regression analysis of tuberculin reactors with various host and environment related factors at $2 \mathrm{~mm}$ cut-off point

\begin{tabular}{|c|c|c|c|c|}
\hline Variable & $\begin{array}{c}\text { No of } \\
\text { cattle } \\
\text { examined }\end{array}$ & $\begin{array}{c}\text { No of positive } \\
(\%)\end{array}$ & $\begin{array}{c}\text { Crude OR } \\
95 \% \mathrm{CI}\end{array}$ & $\begin{array}{l}\text { Adjusted OR } \\
95 \% \mathrm{CI}\end{array}$ \\
\hline \multicolumn{5}{|l|}{ Farm } \\
\hline I & 100 & $7(7)$ & 1 & 1 \\
\hline II & 111 & $20(18.02)$ & $2.92(1.18-7.24)^{*}$ & $6.99(1.63-30.04)^{*}$ \\
\hline III & 100 & $0(0)$ & - & - \\
\hline IV & 100 & $6(6)$ & $0.85(0.27-2.61)$ & $0.79(0.25-2.45)$ \\
\hline $\mathrm{V}$ & 90 & $15(16.67)$ & $2.65(1.03-6.85)^{*}$ & $3.4(1.22-9.50)^{*}$ \\
\hline \multicolumn{5}{|l|}{ Origin } \\
\hline Dubuliq & 289 & $13(4.50)$ & 1 & 1 \\
\hline Moyale & 155 & $23(14.84)$ & $3.70(1.82-7.53)$ & $0.35(0.11-1.10)$ \\
\hline Yabelo & 57 & $12(21.05)$ & $5.66(2.43-13.19) *$ & $-\cdots$ \\
\hline \multicolumn{5}{|l|}{ Age } \\
\hline$\leq 2$ & 109 & $2(1.83)$ & 1 & 1 \\
\hline$>2$ & 392 & $46(11.73)$ & $7.11(1.70-29.79)^{*}$ & $2.10(0.46-9.59)$ \\
\hline \multicolumn{5}{|l|}{ BCS } \\
\hline Medium & 16 & $2(12.50)$ & 1 & 1 \\
\hline Good & 485 & $46(9.48)$ & $0.73(0.16-3.33)$ & $0.89(0.19-4.22)$ \\
\hline
\end{tabular}




\section{Herd prevalence of bovine tuberculosis}

The herd prevalence was $80 \%$ (95\% CI: 76.5-83.5) at $4 \mathrm{~mm}$ and $2 \mathrm{~mm}$ cut-off points. Association of the risk factors with bovine tuberculin reactivity showed farm, origin of the cattle, age and body condition score showed a statistically significant difference among the categories at $4 \mathrm{~mm}$ and $2 \mathrm{~mm}$ of cut of points $(\mathrm{P}<0.05)$.

\section{Prevalence of Mycobacterium avium complex infection}

According to CIDT result of avian tuberculin skin reaction, the overall animal prevalence of Mycobacterium avium complex infection was 0.6\% (95\% CI: 0.081.27) at $4 \mathrm{~mm}$ cut-off point.

\section{Discussion}

Bovine tuberculosis is known to be endemic in cattle of Ethiopia particularly in dairy farms with a prevalence ranging from 0.8 to $46.8 \%$ in different husbandry system and breed of cattle (Gobena Ameni et al., 2003a) based on comparative intradermal tuberculin test (CIDT). However, no information is available on the prevalence of bovine tuberculosis in beef cattle feedlots of Ethiopia particularly on Borena breed managed under private fattening export farms located in and around Adama town.

In the present study, on the basis of CIDT, the prevalence of BTB was $4.39 \%$ at $4 \mathrm{~mm}$ cut-off point and $9.58 \%$ at $2 \mathrm{~mm}$ cut-off point. The prevalence in this study was lower than the prevalence reported in previous studies done on dairy cattle in Ethiopia (Gobena Ameni and Wudie, 2003b). The main reason for this might be related to dairy farm mainly compared of female cross breed which may be affected by their reproduction and milk production status that may lead to stress as compare to male animals that constitute the beef feedlots. Hence dairy animals might be more susceptible than beef animals (Radostits et al., 2007), the difference in husbandry system, functions of animals, organisms, breed of animals and age of animals. In dairy farms where high prevalence of BTB was recorded mainly reared under in-housed intensive husbandry system in which the majority of the cattle were cross breed as compared to the open-air handling system and consisting of local zebu (Borena) breeds in the feedlots. According to previous studies intensive husbandry system and cross breed 
cattles were important risk factors for high prevalence of BTB in the dairy farms (GobenaAmeniet al., 2006; Gobena Ameni et al., 2007).

Similarly, dairy cattle were kept for longer age as compared to the beef cattle which were relatively younger in their age (2 to 5 years), hence, beef cattle had short lifetime for exposure for infection as compared to the dairy cattle which were exposed for longer years to aerosol or oral infection by Mycobacterium species. In the present study, the prevalence of BTB showed an increase with age which is in agreement with previous reports by other researchers in cattle (Alemayehu Regassa et al., 2010; Demelash Biffa et al., 2011).

At $2 \mathrm{~mm}$ cut-off point, statistically significant differences in proportion of bovine positive reactors were observed among feedlot farms, in which Farm II and Farm V showed higher proportion of positive bovine tuberculin reactor than Farm I1. This difference might be related to the origin of cattle from which the animal were purchased and age distribution of the farms that may affect the farm level bovine tuberculin positivity. According to the observation in this study the settings in terms of husbandry, duration of stay in the feed lot and site of the feedlot farms were almost similar, and hence, the difference assumed to be related to the origin of the animals rather than the difference at feedlot level. Previous studies in the Yabello area based on CIDT showed $5.5 \%$ prevalence in extensive pastoral production system and similarly a closer prevalence $(8.7 \%)$ at $4 \mathrm{~mm}$ cut-off points was reported in the present study. Similar to other studies in Ethiopia, there was no association between body condition score and tuberculin skin test positivity (Tschopp et al., 2010). In present study, a high herd level prevalence $(80 \%)$ was observed which might indicate the widespread occurrence of the infection in the feedlot herds as compared to moderately low herd prevalence observed in extensive pastoral production system (Gezahagne Mamo et al., 2013).

\section{Conclusion}

To the best of our knowledge, this is the first BTB study done on export feedlot farms of Ethiopia mainly consisting of Borena breed cattle. The study revealed a low prevalence of bovine tuberculosis in beef cattle and indicated the presence of epidemiological risk factors for infection among cattle of the feedlots such as the origin of the cattle and age of the animal as important factors. Considering the fact that these feedlots established for export of fattened live beef cattle, 
the findings of this study warrants the need of designing a control strategies at feedlot level and testing of animals during the purchase of the cattle at the market place of the animals.

\section{Acknowledgements}

This study was supported by Addis Ababa University through its Thematic Research Program and Hawasa University. The authors acknowledge the incredible support of Endale Mulugeta organizing by contacting with feedlot farm owners and assigning assisting persons from the office. Our acknowledge goes to Dr. Shimelis Bekele and W/t Frehiwot Ayele for assisting us during tuberculin skin testing. At last but not least we gave appreciation to East Shewa Zone Agricultural Office, for the contribution of organizing our activities at feedlot sites.

\section{References}

Ameni, G., Aseffa, A., Engers, H., Young, D., Gordon, S., Hewinson, G. and Vordermeier, M., 2007. High prevalence and increased severity of pathology of bovine tuberculosis in Holsteins compared to Zebu breeds under field cattle husbandry in central Ethiopia. Clin. Vaccine Immunol., 14, 1356-1361.

Ameni, G., Bonner, P. and Tibbo, M., 2003a. Across-sectional study of bovine tuberculosis in selected dairy farms in Ethiopia. Intern. J. Appl. Res. Vet. Med., 1, 85-97.

Ameni, G. and. Wude, A., 2003b. Preliminary study on bovine tuberculosis in Nazareth municipality abattoir of central Ethiopia. Bull Anim. Hlth. Prod. Afri., 51, 125-132

Ameni, G., Aseffa, A., Engers, H., Young, D., Hewinson, G. and Vordermeier, M., 2006. Cattle husbandry in Ethiopia is a predominant factor for affecting the pathology of bovine tuberculosis and gamma interferon responses to mycobacterial antigens. Clin. Vaccine Immunol., 13, 1030-1036.

Ameni, G., Hewinson, G., Aseffa, A., Young, D. and Vordermeier, M., 2008. Appraisal of interpretation criteria for the comparative intradermal tuberculin test for diagnosis of tuberculosis in cattle in central Ethiopia. Clin. Vaccine Immunol., 15 (8), 1272-1276.

Berg, S., Firdessa, R., Habtamu, M., Gadisda, E., Mengistu, A., Yamuah, L., Ameni, G., Vordermeier, M., Robertson, B., Smith, N., Engers, H., Young, D., Hewinson, G., Aseffa, A. and Gordon, S., 2009. The burden of mycobacterial disease in Ethiopian cattle: Implications for Public Health. PloS One, 4(4), e5068. 
Biffa, D., Bogale, A. and Skjerve, E., 2010. Diagnostic efficiency of abattoir meat inspection service in Ethiopia to detect carcasses infected with Mycobacterium bovis: Implications for Public Health. BMC Public Health, 10, 462.

Biffa, D., Inangolet, F., Bogale, A., Oloya, J., Djonne, B. and Skjerve, E., 2011. Risk factors associated with prevalence of tuberculosis-like lesions and associated mycobacteria in cattle slaughtered at public and export abattoirs in Ethiopia. Trop. Anim. Health Prod., 43, 529-538

Cosivi, O., Grange, J.M., Dabron, C.J., Raviglione, M.C., Fujikura, T., Cousins, D., Robinson, R.A., Huchzermeyer, H.F., de-Kantor, I. and Meslin, F.X., 1998. Zoonotic tuberculosis due to Mycobacterium bovis in developing countries. Emerg. Infect. Dis., 4, 1-17.

De-Lahunta, A. and Habel, R.E., 1986. Teeth: Applied Veterinary Anatomy; W. B. Sounders Company. USA, pp. 4-16.

ESMoA, 2015. East Shewa Ministry of Agriculture: Annual report 2015.

Garnier, T., Eiglmeier, K., Camus, J.C., Medina, N., Mansoor, H., Pryor, M., Duthoy, S., Grondin, S., Lacroix, C., Monsempe, C., Simon, S., Harris, B., Atkin, R., Doggett, J., Mayes, R., Keating, L., Wheeler, P.R., Parkhill, J., Barrell, B.G., Cole, S.T., Gordon, S.V. and Hewinson, R.G., 2003. The complete genome sequence of Mycobacterium bovis. Proc. Natl. Acad. Sci., 100, 7877-7882.

Halderman, M., 2004. The Political Economy of Pro-Poor Livestock Policy-Making in Ethiopia In: Initiative P-PLP, editor. Rome, Italy, pp. 1-59.

Mamo, G., Fekadu, A., Yalelet, W., Nesredin, H., Mengistu, L., Getachew, T., Girmay, M., Gunnar, B. and Ameni, G., 2013. Bovine tuberculosis and its associated risk factors in pastoral and agro-pastoral cattle herds of Afar Region, Northeast Ethiopia J. Vet. Med. Anim. Health., 5(6), 171-179.

MoA, 2013. Ministry of Agriculture: Major challenges and achievements in Ethiopian livestock production.

Nicholson, M. J. and Butterworth, M.H., 1986. A guide to condition scoring of zebu cattle; ILCA, Addis Ababa, Ethiopia.

OIE, 2009. Bovine Tuberculosis. OIE manual of diagnostic tests and vaccines for terrestrial manual. World Health Organization for Animal Health, Paris, France. $2,4-7$

Radostits, O.M., Gay, C.C., Blood, D.C. and Hinchclif, K.W., 2007. Veterinary medicine: a text book of the disease of cattle, sheep, pigs, goats and horses. W.B Saunders, London. 
Regassa, A., Tassew, A., Amenu, K., Megersa, B., Abunna, F., Mekibib, B., Macrotty, T. and Ameni, G., 2010. A cross-sectional study on bovine tuberculosis in Hawassa town and its surroundings, Southern Ethiopia. Trop. Anim. Health Prod., 42, 915920.

Richardson, I.W., Bradley, D.G., Higgins, I.M., More, S.J., McClure J. and Berry, D.P., 2014. Variance components for susceptibility to Mycobacterium bovis infection in dairy and beef cattle. Genet Sel. Evol., 46, 77.

Thrusfield, M., 1995. Veterinary epidemiology 2nd ed. Balckwell Publishing Company, Oxford. pp.182-187.

Tschopp, R., Aseffa, A., Schelling, E., Berg, S., Hailu, E., Gadisa, E., Habtamu, M., Argaw, K. and Zinsstag, J., (2010). Bovine tuberculosis at the wildlife-livestockhuman interface in Hamer Woreda, South Omo, Southern Ethiopia. PLoS One, $5(8)$, e12205. 